\title{
RELEVÂNCIA DE COMPOSTOS DE BAIXA MASSA MOLAR PRODUZIDOS POR FUNGOS E ENVOLVIDOS NA BIODEGRADAÇÃO DA MADEIRA
}

\author{
Valdeir Arantes \\ Forestry Products Biotechnology, Department of Wood Science, Faculty of Forestry, University of British Columbia, 2424 Main \\ Mall, Vancouver, British Columbia V6T 1Z4, Canada \\ Adriane M. F. Milagres* \\ Departamento de Biotecnologia, Escola de Engenharia de Lorena, Universidade de São Paulo, CP 116, 12606-810 Lorena - SP, Brasil
}

Recebido em 16/7/08; aceito em 27/1/09; publicado na web em 3/7/09

\begin{abstract}
RELEVANCE OF LOW MOLECULAR WEIGHT COMPOUNDS PRODUCED BY FUNGI AND INVOLVED IN WOOD BIODEGRADATION. Over the last decade, evidences have been shown that the wood biodegradation by fungi is not only a result of the action of their enzymatic machinery but also of various low molecular weight non-enzymatic compounds, especially in fungi that promote brown and white decay, which in nature are the major wood decaying microorganisms. The present review focuses on the recent theories involving these low molecular weight compounds that act direct or synergistically with lignocellulolytic enzymes to attack the wood main macromolecular constituents, their relevance as potential degradative systems, in the overall wood biodegradation, and also outlines their potential biotechnological applications.
\end{abstract}

Keywords: wood biodegradation; enzymes; low molecular weight compounds.

A biodegradação de materiais lignocelulósicos, como a madeira, é um processo natural de reciclagem de matéria orgânica e o entendimento deste processo contribui com a compreensão do ciclo natural do carbono, que tem início na biossíntese dos seus constituintes a partir de $\mathrm{H}_{2} \mathrm{O}, \mathrm{CO}_{2}$ e energia solar e termina com a mineralização destes constituintes e liberação de $\mathrm{CO}_{2}$ e $\mathrm{H}_{2} \mathrm{O}$, em decorrência da decomposição causada principalmente por fungos.

Por muito tempo o processo de biodegradação foi foco de muitos estudos devido à grande quantidade de madeira e produtos à base de madeira, que são danificados por ação de fungos, e devido à necessidade do desenvolvimento de métodos de prevenção à biodegradação menos ofensivos ao meio ambiente. Atualmente, os fungos degradadores de madeira e/ou seus sistemas degradativos têm sido intensivamente estudados em razão do elevado potencial de utilização em aplicações biotecnológicas, como na biodegradação de compostos xenobióticos, ${ }^{1-3}$ biorremediação de solos,${ }^{1,4,5}$ biopolpação da madei$\mathrm{ra}^{6,7}$ e biobranqueamento de polpas celulósicas. ${ }^{8-10}$ Uma vez que o desenvolvimento e a eficácia destes métodos/processos dependem principalmente do conhecimento dos mecanismos químicos e bioquímicos envolvidos na biodegradação dos constituintes da madeira, o entendimento destes mecanismos certamente irá contribuir para o desenvolvimento de novas aplicações, assim como para a melhoria das já existentes.

Apesar do considerável conhecimento adquirido nas últimas décadas a respeito da enzimologia da biodegradação dos constituintes da madeira, até os dias de hoje não se conhecem os mecanismos químicos e bioquímicos exatos empregados pelos fungos durante este processo. Contudo, sabe-se que o processo de biodegradação da madeira por fungos não pode ser explicado unicamente com base na ação das diversas enzimas lignocelulolíticas por eles secretadas. Dentro dessa abordagem, pesquisas recentes têm indicado uma participação expressiva de compostos de baixa massa molar (CBMM). ${ }^{11,12}$

Neste sentido, esta revisão tem como objetivo principal agrupar as diferentes teorias envolvendo CBMM produzidos por fungos degradadores de madeira e enfatizar a importância e a contribuição dos mesmos para a degradação dos principais constituintes macro-

*e-mail: adriane@debiq.eel.usp.br moleculares da madeira (celulose, polioses e lignina), assim como suas aplicações biotecnológicas.

\section{ASPECTOS GERAIS DA COMPOSIÇÃO E BIODEGRADAÇÃO DA MADEIRA}

A madeira é constituída de um arranjo ordenado de células com parede composta basicamente por: ${ }^{13}$

celulose (cerca de 50\%): um homopolímero linear de elevado grau de polimerização/ massa molar, com regiões amorfas e cristalinas, composto unicamente por unidades de $\beta$-D-glucopiranose associadas entre si por ligações $\beta-1,4$ glicosídicas, sendo a celobiose a unidade repetitiva do polímero;

polioses (20-25\%): são heteropolissacarídeos altamente ramificados, amorfos e com baixo grau de polimerização (50-300), formados por xilana, galactana e glicomanana como componentes das cadeias principais e com vários substituintes, como arabinose, galactose, entre outros;

lignina (20-30\%): macromolécula amorfa, composta basicamente por unidades de fenilpropano, contendo subestruturas fenólicas (10$20 \%$ ) e não fenólicas (80-90\%).

Na parede celular, celulose, polioses e lignina estão intimamente associadas e/ou ligadas quimicamente, formando diferentes camadas: a parede primária $(\mathrm{P})$, formada pelas microfibrilas de celulose; e a parede secundária (S), composta principalmente por celulose e lignina, que é formada pelas subcamadas $S_{1}, S_{2}$ e $S_{3}$. As diferentes células encontram-se separadas pela lamela média (ML), rica em lignina. ${ }^{13}$

\section{Biodegradação da madeira}

A biodegradação da madeira na natureza envolve a ação simultânea de diversos micro-organismos, tais como fungos, bactérias e parasitas, dentre os quais os fungos são os mais eficientes. ${ }^{13}$ Entre estes fungos destacam-se os basidiomicetos, que são os principais degradadores. A degradação causada por estes fungos ocorre necessariamente de forma extracelular, uma vez que os componentes da 
madeira devem ser inicialmente despolimerizados até compostos menores que são susceptíveis ao transporte através da parede celular. Estes fungos agem através da penetração de suas hifas pelo lúmen das células, as quais ali instaladas produzem uma variedade de metabólitos extracelulares que vão, assim, atuar degradando os componentes da parede celular vegetal.

As características de crescimento dos micro-organismos na madeira e o tipo de sistema degradativo produzido resultam em diferentes tipos de degradação. ${ }^{14}$ Dependendo do tipo de degradação, diferentes mudanças físicas, químicas e morfológicas ocorrem na madeira. ${ }^{15}$ Com base nestas mudanças produzidas em estágios mais avançados de degradação da madeira por diferentes fungos, três tipos de degradação são sugeridos: branca, parda (ou marrom) e macia (ou branda). As decomposições branca e parda são causadas por fungos basidiomicetos, embora alguns ascomicetos também sejam classificados como fungos de decomposição branca. ${ }^{16}$

De forma geral, os fungos de decomposição parda são associados com coníferas (gimnospermas), e os de decomposição branca com folhosas (angiospermas). ${ }^{17}$

\section{Fungos causadores de decomposição branca e parda}

A característica comum de todos os fungos de decomposição branca é a capacidade de degradar lignina, assim como celulose e polioses. Entretanto, as velocidades relativas de decomposição da lignina e polissacarídeos variam grandemente de acordo com a espécie fúngica. Outra característica comum destes fungos é que a madeira decomposta adquire uma aparência esbranquiçada.

Podem-se diferenciar dois modos distintos de degradação da célula vegetal por estes fungos. O primeiro, e mais comum, é denominado de decomposição branca simultânea, e os carboidratos e lignina são atacados mais ou menos simultaneamente. ${ }^{18}$ Neste caso, é observada uma erosão progressiva da parede celular no sentido lúmen-lamela média, levando à diminuição progressiva e irregular da espessura da parede celular da madeira. ${ }^{16,18,19}$ No outro modo, menos frequente, comumente denominado de decomposição branca seletiva, polioses e lignina são preferencialmente atacadas, notoriamente nos estágios iniciais de degradação ${ }^{18}$ sem a simultânea erosão da parede celular vegetal, ${ }^{19}$ ou seja, a degradação da lignina ocorre em pontos distantes da hifa fúngica. ${ }^{11,16} \mathrm{~A}$ maioria dos fungos de decomposição branca seletiva promove a degradação seletiva principalmente em estágios iniciais de degradação, quando ainda não se observa despolimerização significativa da celulose. Neste caso, a parede celular, apesar de degradada, mantém sua forma original.

Estas duas formas de degradação branca podem ser causadas por um mesmo fungo em diferentes partes da madeira. ${ }^{20}$

Os fungos causadores de decomposição parda degradam principalmente os polissacarídeos (celulose e polioses) presentes na madei$\mathrm{ra}^{21,22}$ ao passo que a lignina é somente modificada estruturalmente, sendo a desmetoxilação a principal alteração ocorrida na estrutura da lignina, com pouca oxidação da cadeia lateral. ${ }^{23,24}$ Entretanto, alguns estudos mais recentes mostram perda substancial de lignina (acima de $20 \%$, lignina Klason) durante a biodegradação da madeira por algumas espécies causadoras de decomposição parda, ${ }^{18,25,26}$ e que esta perda é aumentada em estágios mais avançados de degradação. ${ }^{18,26}$ Todavia, esta perda pode estar associada com a liberação de metanol proveniente das reações de desmetoxilação e não com a degradação da lignina propriamente dita.

A degradação dos polissacarídeos causada por estes fungos não está localizada próxima à hifa fúngica. A camada $\mathrm{S}_{2}$ da parede celular da madeira é intensamente degradada durante o processo de biodegradação, ao passo que a camada $S_{3}$ pode permanecer relativamente intacta até estágios mais avançados de degradação. ${ }^{21,27,28}$
A madeira decomposta por estes fungos tem a aparência de um material marrom que quebra facilmente em cubos, no sentido transversal ao das fibras dos vegetais.

\section{Enzimologia da biodegradação da madeira}

Várias enzimas são produzidas por fungos durante a colonização da madeira e, basicamente, os complexos enzimáticos produzidos constituem-se dos sistemas hidrolítico e oxidativo. As enzimas responsáveis pela degradação da celulose e das polioses são hidrolases que apresentam certa especificidade pelo respectivo substrato, ${ }^{29}$ ao passo que as enzimas envolvidas na degradação da lignina são oxidases e, em geral, são pouco específicas. ${ }^{30}$

Os fungos de decomposição branca produzem todas as enzimas extracelulares necessárias para a hidrólise completa da celulose (endo1,4- $\beta$-glucanase, exo-1,4- $\beta$-glucanase e $1,4-\beta$-glicosidase), embora o nível de cada atividade enzimática varie entre os fungos. Em geral, eles não são bons produtores de celulases e a seletividade por lignina de alguns está relacionada a uma atividade de celulase total baixa. Os fungos de decomposição parda produzem endo-1,4- $\beta$-glucanase e 1,4- $\beta$-glicosidase, mas não a exo-1,4- $\beta$-glucanase, que atua nas regiões cristalinas da celulose clivando as ligações glicosídicas a partir do grupo terminal não redutor, liberando unidades de glicose e celobiose. ${ }^{31}$ Dessa forma, a degradação da celulose, característica comum destes fungos, não pode ser explicada unicamente pela ação enzimática.

Celobiose-desidrogenase $(\mathrm{CDH})$ é outra enzima que também participa do complexo celulolítico de alguns fungos, porém possui atividade oxidativa e não hidrolítica. A CDH oxida vários açúcares como celobiose, oligômeros de glicose, lactose e até mesmo celulose. ${ }^{32} \mathrm{O}$ mecanismo de ação da $\mathrm{CDH}$ será discutido em mais detalhes a seguir.

Contrariamente à degradação enzimática da celulose, em que se necessitam somente enzimas que hidrolisem ligações $\beta-1,4$ glicosídicas, a degradação enzimática das polioses requer um conjunto enzimático mais complexo, uma vez que diferentes tipos de ligações e unidades monoméricas estão presentes na sua estrutura de heteropolissacarídeo ramificado. A completa degradação das polioses requer a ação de uma série de enzimas hidrolíticas, sendo as principais endo-1,4- $\beta$-xilanase e $\beta$-xilosidase, e de enzimas acessórias, como $\alpha$-glucuronidase, $\alpha$-L-arabionofuranosidase, acetil esterase, mananases e galactanases. ${ }^{33}$

A biodegradação efetiva da lignina é observada somente com fungos de decomposição branca. Neste processo atuam um grupo de enzimas oxidativas que compreendem: duas peroxidases, ligninaperoxidase ( $\mathrm{LiP})$ e peroxidase dependente de manganês $(\mathrm{MnP})$, que são heme proteínas capazes de oxidar subestruturas da lignina na presença de peróxido de hidrogênio; ${ }^{29,34,35}$ e uma oxidase, a lacase, uma cupro-proteína que catalisa a redução de $\mathrm{O}_{2}$ a $\mathrm{H}_{2} \mathrm{O}$, com simultânea oxidação de subunidades fenólicas da lignina. ${ }^{29,34} \mathrm{~A}$ LiP apresenta potencial de oxidação suficientemente elevado para abstrair elétrons de subestruturas fenólicas e não fenólicas, ao passo que MnP, que apresenta menor potencial de oxidação, é capaz somente de abstrair elétrons de subunidades fenólicas.

Embora sem participação direta na degradação e/ou modificação da lignina, a glioxal oxidase e a aril álcool oxidase são enzimas extracelulares que participam da produção de peróxido de hidrogênio, indispensável para a ação das peroxidases..$^{29,34,36}$

A existência de espécies de fungos de decomposição branca que degradam eficientemente a lignina e somente produzem lacase e/ou $\mathrm{MnP}$, e aquelas que produzem LiP além de lacase e/ou MnP, lançou dúvidas quanto à forma com que fungos de decomposição branca oxidam a lignina e, também, sobre a real participação e exata fun- 
ção que cada uma dessas enzimas exerce no processo de oxidação. Contudo, estudos indicam que a biodegradação da lignina não pode ser efetuada eficientemente somente pelas enzimas ligninolíticas. ${ }^{37}$ Um exemplo é a existência de alguns fungos de decomposição branca que são eficientes degradadores de madeira e que não produzem LiP, como Ceriporiopsis subvermispora e Pycnoporus cinnabarinus, entre outros. ${ }^{34}$ Nestes fungos, a completa degradação da lignina não pode ser explicada unicamente pela ação enzimática quando LiP não é produzida, uma vez que a maior parte da lignina presente na madeira é lignina não fenólica, a qual é somente oxidada pela LiP, evidenciando a participação de outro(s) sistema(s) oxidativo(s) responsável(eis) pela completa degradação da lignina na ausência dessa enzima.

\section{CBMM ENVOLVIDAS NA BIODEGRADAÇÃO DA MADEIRA}

\section{Evidências da participação de CBMM na biodegradação da madeira}

A biodegradação da madeira por fungos causadores de decomposição parda e branca seletiva não ocorre na região imediata da hifa. Nesse sentido, as enzimas lignocelulolíticas extracelulares produzidas por esses fungos no lúmen teriam então que se difundir na parede celular através da camada $S_{3}$, para causar a extensiva degradação dos polissacarídeos na camada $S_{2}$ (no caso da decomposição parda), e da lignina na parede celular e lamela média (no caso da degradação branca seletiva). No entanto, embora estes fungos secretem inúmeras enzimas lignocelulolíticas que são requeridas para a biodegradação destes componentes da madeira, sabe-se que estas enzimas são de elevada dimensão molecular para penetrarem na parede celular da madeira intacta em tempos curtos de biodegradação. ${ }^{11,12}$ Um conjunto de resultados recentes reforça a hipótese de que a degradação da matriz lignocelulósica da madeira não é resultado somente da atividade enzimática, mas é principalmente resultado da ação de agentes não enzimáticos de baixa massa molar ${ }^{11,12}$ Neste contexto, os fungos causadores de decomposição branca seletiva e parda devem produzir compostos com massa molar relativamente baixa, os quais poderiam, então, se difundir pela parede celular e degradar os componentes ali existentes. Com isso, a parede celular seria desestruturada a ponto de permitir a subsequente penetração das enzimas lignocelulolíticas, o que ocorreria nos estágios mais avançados de degradação.

Muitos trabalhos sugerem que as enzimas envolvidas na biodegradação dos componentes macromoleculares da madeira são de elevada dimensão molecular para penetrarem na parede celular intacta, porém poucos trabalhos realmente demonstram a impermeabilidade das enzimas lignocelulolíticas na parede celular nos estágios iniciais de biodegradação. Dentre estes, Srebotnik et al..$^{38}$ e Messner e Srebotnik ${ }^{39}$ observaram que a LiP e proteínas de alta massa molar não difundem na parede celular até que estágios avançados de degradação sejam evidentes. Mais tarde, Blanchette et al. utilizando proteínas como marcadores mostraram claramente que durante a degradação de Pinus sp. por $C$. subvermispora, um fungo causador de degradação branca seletiva, a porosidade da parede celular gradualmente aumenta com o aumento do tempo de biodegradação. ${ }^{11}$ Estes autores verificaram que a insulina $(5.730 \mathrm{Da})$, que possui massa molar muito inferior às enzimas lignocelulolíticas, penetrou em regiões mais externas da parede secundária após duas semanas de incubação, enquanto a mioglobina (17.600 Da) penetrou na parede celular somente após quatro semanas de degradação, quando uma alteração apreciável da parede celular começou a ser observada. Estes resultados indicam que proteínas com tamanho similar como, por exemplo, as xilanases são aparentemente impedidas de penetrar na parede secundária até que uma alteração apreciável da mesma tenha ocorrido. Ovalbumina (44.287 Da), que possui massa molar similar à LiP, MnP e outras enzimas degradativas, permeou na parede celular vegetal somente após oito semanas de degradação, quando a madeira já estava em estágios bem avançados de decomposição e com extensiva desruptura da parede celular. ${ }^{11}$

Somado a estas evidências está o fato de que o grupo heme da LiP está localizado na parte interior da proteína e apresenta somente uma pequena abertura, a qual conecta o sítio ativo com a parte externa da enzima ${ }^{40}$ onde somente moléculas pequenas podem se difundir para dentro e para fora desta abertura. De fato, não existem evidências de que uma macromolécula como a lignina possa acessar o sítio ativo através desta abertura. ${ }^{40,41}$ Assim, o envolvimento de compostos de baixa massa molar atuando como mediadores torna-se plausível.

Todos esses antecedentes, e outros existentes na literatura, reforçam a teoria de que a biodegradação da matriz lignocelulósica da madeira não é resultado somente da ação enzimática, mas, também, é resultado da ação de diversos agentes não enzimáticos de baixa massa molar, principalmente nos estágios iniciais de biodegradação.

Os CBMM produzidos como resultado do metabolismo de fungos de decomposição branca e/ou parda até agora identificados e relacionados à degradação dos componentes da parede celular da madeira estão listados na Tabela 1. A atuação direta ou associada às enzimas ligninolíticas compõe diferentes sistemas degradativos e promove a geração de diferentes espécies oxidativas de baixa massa molar, que atuam sobre os componentes da parede celular vegetal.

Tabela 1. CBMM produzidos por fungos degradadores de madeira, seus respectivos sistemas degradativos propostos e o(s) componente(s) alvo

\begin{tabular}{lccc}
\hline CBMM & Sistema Degradativo & Tipo de Degradação & Componente Alvo \\
\hline ácido 3-hidroxi-antranílico & lacase/mediador & branca & lignina \\
ácidos carboxílicos ${ }^{(a)}$ & oxalato (ataque direto) & branca, parda & celulose e polioses \\
& oxalato-Mn ${ }^{3+} / \mathrm{MnP}$ & branca & lignina \\
ácidos graxos insaturados ${ }^{(b)}$ & peroxidação de ácidos graxos & branca & lignina \\
álcool veratrílico (AV) & AV-LiP & branca & lignina \\
& AV-LiP/oxalato-Mn ${ }^{3+}$ & branca & lignina \\
compostos aromáticos clorados $(\mathrm{CACl})^{(c)}$ & CACl-LiP & branca & lignina \\
compostos fenólicos redutores de Fe ${ }^{3+}$ & reação de Fenton mediada & branca, parda & celulose, polioses e lignina \\
peptídeos & reação de Fenton mediada & branca, parda & celulose, polioses e lignina \\
\hline
\end{tabular}

Exemplos: ${ }^{\mathrm{a}}$ ácido oxálico; ${ }^{\mathrm{b}}$ ácido linoléico; ${ }^{\mathrm{c}}$ 2-cloro-1,4-di-metoxi-benzeno. 


\section{Lacase/mediador}

A lacase, com seu relativo baixo potencial redox (cerca de 0,6-0,8 V) está restrita a reagir somente com substâncias facilmente oxidáveis, como fragmentos fenólicos de lignina. ${ }^{42}$ Apesar disso, a inclusão de substâncias oxidáveis de baixa massa molar, conhecidas como mediadores, expande a atividade oxidativa desta enzima. ${ }^{43,44}$

Um mediador é uma molécula de baixa massa molar que atua como um carreador de elétrons. Após ser oxidado pela enzima, difunde-se para fora do sítio ativo e ao encontrar o substrato retira seus elétrons, que não são diretamente oxidados pela enzima por impedimentos estéricos ou termodinâmicos. Dessa forma, este processo pode levar a um mecanismo de oxidação que não seria possível para a enzima sozinha, estendendo, assim, a faixa de substratos oxidáveis. ${ }^{45,46}$

Diversos compostos sintéticos têm sido descritos como mediadores eficientes de lacase, entretanto, o ácido 3-hidroxi-antranílico, um metabólito produzido pelo fungo de decomposição branca $P$. cinnabarinus, é o único mediador natural de lacase descrito até o momento, o qual proporciona a formação de um radical capaz de degradar porções de lignina não fenólica. ${ }^{47}$ Por outro lado, Li et al. mostraram que um mutante de $P$. cinnabarinus, deficiente na produção deste ácido, foi capaz de degradar eficientemente lignina, sugerindo que a presença deste mediador não foi necessária para a degradação efetiva da lignina ou que o fungo possa ter utilizado um outro mecanismo para a degradação. ${ }^{48}$ Resultados mais recentes demonstraram que compostos modelo de lignina foram eficientes mediadores de lacase,${ }^{49}$ indicando um possível envolvimento dos produtos de degradação da lignina e extrativos solúveis de baixa massa molar como mediadores naturais de lacase durante a biodegradação da madeira por fungos de decomposição branca, principalmente nos estágios iniciais de biodegradação.

\section{Álcool veratrílico-LiP}

O álcool veratrílico (álcool 3,4-dimetoxi-benzílico, AV) é um metabólito secundário de baixa massa molar produzido e acumulado no meio de cultura de fungos de decomposição branca, ${ }^{50,51}$ principalmente aqueles que secretam LiP. ${ }^{52}$

$\mathrm{O} A V$ pode atuar como um mediador redox difusível da LiP. Neste mecanismo, a oxidação de $\mathrm{AV}$ envolve a transferência de um elétron do composto I (espécie enzimática ativa), formado pela oxidação da enzima nativa com $\mathrm{H}_{2} \mathrm{O}_{2}$, levando à formação de um radical catiônico $\left(\mathrm{AV}^{\bullet+}\right),{ }^{41,42,51,53,54}$ ao passo que o composto I é reduzido ao composto II. Este radical catiônico, de elevado potencial oxidativo e baixa massa molar, poderia então se difundir na parede celular vegetal e iniciar a degradação da lignina.

Um ponto crucial para determinar se AV pode atuar como um mediador redox difusível é estabelecer o tempo de vida da espécie $\mathrm{AV}^{\bullet+}$, sendo que somente um radical com um tempo de vida suficientemente longo poderia se difundir a certa distância da enzima, induzindo a oxidação da lignina. Algumas tentativas foram feitas para medir o tempo de vida do $\mathrm{AV}^{\bullet+}$. Em três estudos, este radical foi gerado quimicamente e sua decomposição foi monitorada espectrofotometricamente e a constante de velocidade de decomposição de primeira ordem foi de $17 \mathrm{~s}^{-1}$, que corresponde a um tempo de meia vida de $41 \mathrm{~ms}$, ou seja, um valor considerado pelos autores suficiente para permitir a oxidação de uma macromolécula a uma considerável distância da enzima. ${ }^{55-57}$ Isto fornece evidência para a teoria de que $\mathrm{AV}^{*+}$ pode servir como um mediador redox difusível entre LiP e a lignina. Contrariamente, Khindaria, Yamazaki e Aust encontraram um valor completamente diferente para a decomposição do $\mathrm{AV}^{\bullet+}\left(1,2 \times 10^{-3} \mathrm{~s}^{-1}\right.$, tempo de meia vida $0,58 \mathrm{~ms}$ ), também gerado quimicamente, porém monitorado por ressonância paramagnética eletrônica ${ }^{58,59} \mathrm{Com}$ este valor, $\mathrm{AV}^{\bullet+}$ poderia não ser estável o suficiente para atuar como um oxidante difusível. Entretanto, quando $\mathrm{AV}^{\bullet+}$ foi gerado pela oxidação com LiP, a velocidade de decomposição foi muito lenta $\left(1,85 \mathrm{~s}^{-1}\right)$. Assim, a formação de um complexo LiPII- $\mathrm{AV}^{\cdot+}$ com tempo de vida maior foi sugerido como a espécie que atua na oxidação da lignina. Com base nessas observações, os autores sugeriram que $\mathrm{AV}^{*+}$ gerado enzimaticamente pode atuar como um mediador redox somente como uma espécie ligada à enzima, e não como um oxidante difusível. ${ }^{58,59}$

Por outro lado, Popp, Kalyanaraman e Kirk demonstraram que na presença de ácido oxálico (ou malônico) e $\mathrm{AV}, \mathrm{Mn}^{2+}$ é oxidado a $\mathrm{Mn}^{3+}$ indiretamente por LiP. O mecanismo proposto pelos autores depende da oxidação do oxalato por $\mathrm{AV}^{\bullet+}$, resultando na formação do radical ânion carboxilato $\left(\mathrm{CO}_{2}^{\circ}\right)$, que reduz $\mathrm{O}_{2}$ ao radical superoxiânion $\left(\mathrm{O}_{2}{ }^{*}\right)$, que por sua vez oxida $\mathrm{Mn}^{2+}$ a $\mathrm{Mn}^{3+} \cdot{ }^{60} \mathrm{~A}$ produção de $\mathrm{Mn}^{3+}$ é importante porque ele pode servir como um oxidante difusível quando adequadamente quelado (para promover estabilização de $\mathrm{Mn}^{3+}$ ) como, por exemplo, pelo ácido oxálico, como descrito em detalhes mais adiante.

\section{Compostos aromáticos clorados-LiP}

Em uma revisão da literatura feita a pouco mais de uma década, de Jong e Field relacionaram 81 compostos halogenados produzidos por 46 gêneros diferentes de basidiomicetos, principalmente fungos de decomposição branca. Dentre estes compostos, 66 eram aromáticos halogenados produzidos por 35 gêneros diferentes, sendo os mais comuns os metoxi-benzílicos clorados. ${ }^{61}$

Por meio de vários trabalhos o grupo de Teunissen demonstrou que o metabólito 2-cloro-1,4-dimetoxi-benzeno pode atuar como um mediador de baixa massa molar da LiP. ${ }^{62,63}$ A partir de análises por ressonância paramagnética eletrônica e espectrofotometria de UV/ visível, os autores mostraram a formação de um radical relativamente estável durante a oxidação de 2-cloro-1,4-dimetoxi-benzeno por LiP, indicando uma possível habilidade deste radical em difundir-se a certa distância da enzima. ${ }^{63}$ De acordo com ten Have e Teunissen vários autores têm mostrado que 2-cloro-1,4-dimetoxi-benzeno pode substituir AV na oxidação de corantes azo e do corante polimérico Poly R-478 por LiP, sendo que os azo somente foram oxidados na presença de mediador. ${ }^{42}$ Todavia, ainda não é certo se 2-cloro-1,4dimetoxi-benzeno está na verdade envolvido na biodegradação da lignina, uma vez que sua biossíntese não coincide com a produção de LiP, como mostrado para AV. ${ }^{42}$ Recentemente, Arantes identificou vários compostos aromáticos clorados de baixa massa molar no cultivo do fungo de decomposição branca seletiva Perenniporia medulla-panis que aparentemente é deficiente em LiP, e sugeriu que na ausência de LiP estes compostos poderiam atuar como substratos da aril álcool oxidase para a produção de peróxido de hidrogênio, o qual é requerido para a atuação da $\mathrm{MnP}$ e, também, para a geração de radicais hidroxilas pela reação de Fenton. ${ }^{64} \mathrm{~A}$ produção de peróxido de hidrogênio pela aril álcool oxidase utilizando compostos organoclorados foi também reportada por ten Have e Teunissen. ${ }^{42}$

\section{Peroxidação de ácidos graxos}

Ácidos graxos são encontrados naturalmente na madeira (extrativos) ou produzidos durante a sua biodegradação. ${ }^{13}$ A peroxidação de ácidos graxos insaturados gera radicais livres, principalmente o radical peroxila, que possuem potencial de oxidação suficientemente elevado para oxidar as subestruturas não fenólicas da lignina, e tem sido sugerida como uma via oxidativa para explicar a abstração de elétrons de subestruturas não fenólicas da lignina por fungos de decomposição branca deficientes em LiP. ${ }^{65-69}$

Basicamente o processo de peroxidação de ácidos graxos consiste 
na incorporação de oxigênio molecular a um ácido graxo insaturado (R) para produzir um hidroperóxido $(\mathrm{ROOH})$ como produto primário inicial. Este processo pode ser dividido em três etapas: iniciação, propagação e terminação. ${ }^{64}$

Durante a biodegradação da madeira, a peroxidação de ácidos graxos poderia ser mediada por $\mathrm{Mn}^{3+}$ gerado pela $\mathrm{MnP},{ }^{70}$ metais de transição (como $\mathrm{Fe}^{2+}$ e $\mathrm{Cu}^{1+}$ ), radicais hidroxila $(\mathrm{HO} \bullet)$ e hidroperoxila $(\mathrm{HOO} \bullet)^{71} \mathrm{Fe}^{3+}$ ou $\mathrm{Fe}^{3+}$-complexado pode iniciar as reações de peroxidação desde que um agente redutor esteja presente para reduzir $\mathrm{Fe}^{3+}$ a Fe${ }^{2+}$.

Recentemente, Kapich, Galkin e Hatakka demonstraram que ácidos fenólicos sintéticos e uma mistura de compostos fenólicos naturais inibem, mas não previnem, a peroxidação do ácido graxo insaturado ácido linoléico mediada por $\mathrm{MnP}$ e, também, a degradação de compostos modelo de lignina não fenólica. ${ }^{73} \mathrm{~A}$ inibição da peroxidação do ácido linoléico foi afetada principalmente por compostos com hidroxilas fenólicas livres e parece ser proporcional à quantidade dessas hidroxilas. ${ }^{73}$ Alguns compostos aromáticos hidroxilados inibem totalmente a peroxidação de lipídeos, outros apenas reduzem a velocidade da reação de peroxidação. As subestruturas de lignina não fenólicas podem assim ser degradadas mesmo na presença de ácidos fenólicos.

Srebotnik e Boisson demonstraram que lacase na presença de um mediador fenólico, como o ácido 4-hidroxi-benzóico ou uma preparação de lignina fenólica, pode catalisar reações que resultem na peroxidação do ácido linoléico, as quais foram largamente estimuladas quando o meio reacional continha $\mathrm{Mn}^{2+} .{ }^{38}$ Os autores demonstraram que os radicais fenoxila formados podem oxidar $\mathrm{Mn}^{2+}$ a $\mathrm{Mn}^{3+}$, que inicia a peroxidação do ácido linoléico, como já descrito para as reações de peroxidação catalisadas por $\mathrm{MnP} \cdot{ }^{38}$ Contudo, até o momento ainda não foi descrita a degradação de porções de lignina não fenólica pelo sistema lacase/peroxidação de ácidos graxos.

\section{Ácido oxálico}

Várias funções importantes têm sido atribuídas ao ácido oxálico durante a biodegradação da madeira, tanto por fungos de decomposição branca quanto parda. ${ }^{12,74,75}$

Vários trabalhos sugerem que o ácido oxálico pode atuar de forma direta, seja através de um ataque sobre a celulose e polioses na madeira provocando hidrólise ácida, ou pelo abaixamento do $\mathrm{pH}$ no microambiente próximo à hifa fúngica, protegendo o fungo, por exemplo, contra a geração de espécies de oxigênio reativo (ROS) próximo à hifa. ${ }^{12}$ De acordo com Lequart et al., o ácido oxálico poderia, também, reduzir $\mathrm{MnO}_{2}$ presente na madeira na forma de precipitados escuros a $\mathrm{Mn}^{2+}, \mathrm{Mn}^{3+}$ e outras espécies oxidantes que promovem reações de oxidação da lignina, atacam as microfibrilas de celulose, causando uma disruptura estrutural, ${ }^{76} \mathrm{o}$ que facilitaria o processo de degradação enzimática. O ácido oxálico pode, também, quelar cálcio da parede celular, o que provocaria o aumento da porosidade da parede celular e a desestruturação entre microfibrilas, facilitando, assim, a degradação enzimática. ${ }^{77}$ Por outro lado, Jellison et al. sugeriram que a formação de oxalato de cálcio pode ser considerada também uma forma de proteção do fungo quanto à toxicidade do ácido oxálico em excesso. ${ }^{78}$

Ácido oxálico também pode atuar de forma indireta, auxiliando a ação de outros metabólitos ou sistemas reacionais para degradar os componentes da madeira. Por exemplo, o grupo de Goodell sugere que o ácido oxálico produzido por fungos de decomposição parda auxilia a reação de Fenton, solubilizando $\mathrm{Fe}^{3+}$ e transportando-o de microrregiões de $\mathrm{pH}$ mais ácido (ao redor da hifa fúngica) para microrregiões na madeira com o pH menos ácido, permitindo, então, a redução de $\mathrm{Fe}^{3+}$ por compostos fúngicos redutores de ferro e a for- mação de radical hidroxila pela reação de Fenton a certa distância da hifa fúngica. ${ }^{12,28}$ Outros grupos sugerem que o ácido oxálico produzido por fungos de decomposição branca tem um papel fundamental na difusão de $\mathrm{Mn}^{3+}$, proveniente da oxidação de $\mathrm{Mn}^{2+}$ no ciclo catalítico da MnP. Oxalato quela $\mathrm{Mn}^{3+}$ e o complexo estável $\mathrm{Mn}^{3+}$-oxalato oxida as subestruturas de ligninas não fenólicas distantes da $\mathrm{MnP},{ }^{66}$ ou seja, em pontos distantes da hifa. ${ }^{79}$ Oxalato pode, também, atuar como um mediador natural de MnP e LiP durante o processo de biodegradação, uma vez que estas enzimas são capazes de decompor oxalato na presença de $\mathrm{Mn}^{3+}$ ou $\mathrm{AV}$, respectivamente. ${ }^{42} \mathrm{~A}$ quebra do oxalato resulta na geração de $\mathrm{CO}_{2}{ }^{-}$, que é em seguida oxidado por $\mathrm{O}_{2}$ para gerar $\mathrm{O}_{2}{ }^{-}$, radical este também sido sugerido como agente oxidativo de várias reações de oxidação da lignina. ${ }^{42}$

Por outro lado, tem-se que durante o processo de biodegradação da madeira por fungos de decomposição parda, oxalato pode ser produzido em concentrações inibitórias para a reação de Fenton. Schimidt et al. reportaram que a degradação de celulose pelo sistema Fenton in vitro é inibida por elevadas concentrações de ácido oxálico. ${ }^{80}$ Entretanto, elevadas concentrações extracelulares de ácido oxálico em fungos de decomposição parda podem auxiliar no abaixamento do $\mathrm{pH}$ extracelular na madeira, mobilizar $\mathrm{Fe}^{3+}$ e prevenir a geração de radicais hidroxila pela reação de Fenton próximo à hifa fúngica, o que seria danoso para o próprio fungo. ${ }^{12,81}$

Contudo, embora diversas funções tenham sido atribuídas ao ácido oxálico durante a biodegradação da madeira por fungos de decomposição branca e parda, ainda não se sabe ao certo como sua concentração é regulada no ambiente próximo à hifa fúngica.

\section{Reação de Fenton}

A reação de Fenton é baseada na reação entre peróxidos (normalmente $\mathrm{H}_{2} \mathrm{O}_{2}$ ) e ferro (normalmente $\mathrm{Fe}^{2+}$ ) em meio ácido para a formação de ROS, principalmente o radical hidroxila $(\bullet \mathrm{OH})\left(\mathrm{Fe}^{2+}+\right.$ $\left.\mathrm{H}_{2} \mathrm{O}_{2} \rightarrow \mathrm{Fe}^{3+}+\cdot \mathrm{OH}+{ }^{-} \mathrm{OH}\right)$.

A teoria de que fungos decompositores de madeira utilizam ROS para degradar madeira data da segunda metade do século passado..$^{82,83}$ Em 1965, Halliwell observou que o radical hidroxila, ou um agente oxidante similar, gerado pela reação de Fenton era destrutivo à celulose, e foi o primeiro a propor a existência de um sistema celulolítico não enzimático envolvendo ferro e peróxido durante a biodegradação da madeira. ${ }^{82}$ Subsequentemente, Koenigs demonstrou que celulose na madeira pode ser despolimerizada pelos reagentes de Fenton $\left(\mathrm{Fe}^{2+}\right.$ $+\mathrm{H}_{2} \mathrm{O}_{2}$ ), que fungos de decomposição parda produzem peróxido de hidrogênio extracelular e que a madeira contém ferro suficiente para suportar a hipótese de Halliwell. ${ }^{82-87}$ Vários outros trabalhos da época também sugeriram a participação da reação de Fenton durante a biodegradação da madeira, após demonstrarem a similaridade entre a celulose degradada pela reação de Fenton e por fungos de decomposição parda ${ }^{88,89}$ Estudos mais recentes com fungos de decomposição parda crescidos em meio líquido definido demonstram que estes fungos usam radicais hidroxila para iniciar a degradação de vários polímeros sintéticos e organopoluentes..$^{90-94}$

O radical hidroxila pode abstrair hidrogênio de subunidades de açúcar de polissacarídeos como a celulose, com elevada constante de velocidade $\left(\sim 10^{9} \mathrm{M}^{-1} \mathrm{~s}^{-1}\right) .{ }^{95}$ Estas reações produzem radicais centrados no carbono que reagem rapidamente com $\mathrm{O}_{2}$ gerando espécies $\mathrm{ROO}^{\bullet}$. Se este radical organo-peroxila já tiver um grupo hidroxila no mesmo carbono, ${ }^{\bullet} \mathrm{OOH}$ é eliminado. Entretanto, se o radical não tiver um grupo $\alpha$-hidroxila, ele sofre uma variedade de reações de oxi-redução, algumas das quais resultam na quebra da cadeia polissacarídica ${ }^{65} \mathrm{e}$ na geração de ácido glucônico (como a lactona), que é uma reação, também, promovida por fungos de decomposição parda durante a biodegradação da madeira in vivo ${ }^{89}$ 
Estudos com compostos modelo de lignina indicam que ${ }^{\bullet} \mathrm{OH}$ ataca subunidades da lignina com elevada constante de velocidade (ao redor de $10^{10} \mathrm{M}^{-1} \mathrm{~s}^{-1}$ ) tanto para a abstração de hidrogênio do $\mathrm{C}_{\alpha}$ quanto pela adição ao anel aromático. ${ }^{95}$ Reações típicas de $\bullet \mathrm{OH}_{\text {com a lignina }}$ incluem desmetoxilação, hidroxilação e oxidação do $\mathrm{C}_{\alpha}$. Quando ocorre a abstração de hidrogênio, o produto é uma cetona benzílica, ao passo que a adição ao anel forma um radical ciclo-hexadienil hidroxilado que, em condição ácida, pode reagir com um próton e eliminar água, assim, gerando um radical aril que sofre quebra da ligação carbono-carbono e outras reações degradativas. ${ }^{96}$ Por outro lado, dados publicados indicam que é mais provável que o radical ciclo-hexadienil se decomponha em outros produtos, no qual o anel aromático se torna hidroxilado. ${ }^{96,97}$ Por exemplo, quando a adição de OH ocorre em posição não substituída do anel, o radical é oxidado e perde um próton para introduzir um novo grupo hidroxila fenólico. Quando uma posição com um substituinte metoxila é atacada, metanol é eliminado e um radical fenoxila é produzido. A redução deste intermediário resulta em uma hidroxila fenólica na posição inicial do grupo metoxila, a menos que ele se polimerize. ${ }^{96}$ Uma reação análoga é o ataque na posição do anel que contém uma ligação $\beta-\mathrm{O}-4$, mas nesse caso ocorre a quebra da macromolécula. ${ }^{97}$

Estes estudos mostram que a oxidação da lignina por ${ }^{\bullet} \mathrm{OH}$ resulta em várias reações similares ao ataque por fungos de decomposição parda, que durante a biodegradação modificam a lignina principalmente através de desmetoxilação/ hidroxilação, ${ }^{23,24,98}$ o que evidencia uma possível participação de $\bullet \mathrm{OH}$ durante a modificação oxidativa da lignina por fungos de decomposição parda.

A partir de todas essas evidências e muitas outras encontradas na literatura, a reação de Fenton parece ser uma rota plausível para explicar a produção de ROS durante a biodegradação da madeira.

Múltiplas teorias têm sido propostas para explicar a geração de $\mathrm{Fe}^{2+}$ a partir do $\mathrm{Fe}^{3+}$ presente na madeira na forma de hidr(óxidos) insolúveis e a produção de peróxido de hidrogênio extracelular. As vias até agora propostas para a produção do reagente de Fenton $\left(\mathrm{Fe}^{2+} \mathrm{e}_{2} \mathrm{O}_{2}\right)$ in vivo incluem a participação de vários CBMM com capacidade de reduzir $\mathrm{Fe}^{3+}$ a Fe ${ }^{2+}$ (peptídeos e compostos aromáticos) além da enzima $\mathrm{CDH}$.

\section{Peptídeos}

A primeira evidência do possível envolvimento de metabólitos extracelulares de natureza protéica na geração de radicais hidroxilas por fungos degradadores de madeira foi sugerida pelo grupo de Enoki e Tanaka, quando observaram uma relação entre a oxidação da celulose (papel de filtro) e de monômeros de lignina com a oxidação do ácido 2-ceto-4-tiometilbutírico (KTBA) por frações proteicas extracelulares parcialmente purificadas de fungos de decomposição parda.$^{99}$ Os autores observaram que a produção de etileno a partir da oxidação de KTBA pelas frações protéicas era inibida, quando a mistura reacional contendo proteinas extracelulares foi autoclavada previamente à adição de KTBA ou quando as reações de oxidação de KTBA foram conduzidas na presença de sequestradores de radicais hidroxila. ${ }^{99}$

Em vários trabalhos posteriores o mesmo grupo isolou os metabólitos proteicos extracelulares a partir de culturas de fungos de decomposição branca e parda cultivados em cavacos de madeira. ${ }^{31,100-105}$ Os compostos parcialmente purificados foram caracterizados como glicopeptídeos de baixa massa molar (1-5 kDa) capazes de quelar $\mathrm{Fe}^{3+}$, reduzir $\mathrm{Fe}^{3+}$ a Fe ${ }^{2+}$ e com elevada afinidade por $\mathrm{Fe}^{2+}$. Estes metabólitos foram capazes de catalisar reações de oxi-redução entre $\mathrm{O}_{2}$ e doadores de elétrons, como o NADH (nicotinamida-adenina-dinucleotídeo reduzido), produzindo $\mathrm{H}_{2} \mathrm{O}_{2}$ via $\mathrm{O}_{2}{ }^{-}$, que então reagiu com o $\mathrm{Fe}^{2+}$ para gerar radicais hidroxilas..$^{31,100-105} \mathrm{Com}$ base nestes resultados, o grupo sustenta a teoria de que no estágio inicial de degradação da parede celular da madeira por fungos causadores de decomposição branca e parda, ocorre a secreção de glicopeptídeos de baixa massa molar, os quais reduzem $\mathrm{Fe}^{3+}$ presente na madeira e se complexam com o $\mathrm{Fe}^{2+}$ gerado. O complexo glicopeptídeo- $\mathrm{Fe}^{2+}$ então catalisa reações de oxiredução entre $\mathrm{O}_{2}$ e um doador de elétrons para produzir peróxido de hidrogênio. Posteriormente, outro complexo glicopeptídeo-Fe ${ }^{2+}$ reduz o peróxido de hidrogênio gerando radicais hidroxilas via reação de Fenton. O radical hidroxila formado ataca oxidativamente os constituintes da madeira. ${ }^{100,102,104}$ Este modelo oxidativo de baixa massa molar ainda requer mais estudos, uma vez que até o momento não há trabalhos que reportem a produção extracelular de NADH por fungos degradadores de madeira. Além disso, se este modelo for realmente utilizado por estes fungos, é provável que algum outro composto atue como doador de elétron ao invés de NADH.

Através de vários trabalhos, o grupo de Gao também propôs a participação de peptídeos de baixa massa molar na produção de radicais hidroxilas via reação de Fenton, tanto em fungos de decomposição branca, quanto em fungos de decomposição parda. ${ }^{106-110}$

Wang e Gao isolaram e purificaram um peptídeo de baixa massa molar de culturas de G. trabeum contendo cavacos de madeira. A composição de aminoácidos foi Asp-Thr-Ser-Glu-Gly-Ala-Cys-ValMet-Ile-Leu-Tyr-Phe-Lys-Arg-Trp e, de acordo com a análise de aminoácidos, a massa molar mínima foi estimada em $4 \mathrm{kDa} \cdot{ }^{106,107}$ Este metabólito teve alta termoestabilidade (somente $20 \%$ da atividade foi perdida após $24 \mathrm{~h}$ a $60^{\circ} \mathrm{C}$ ), apresentou ponto isoelétrico (pI) 6,6 , teve alta afinidade por $\mathrm{Fe}^{3+}$ e apresentou capacidade de reduzir $\mathrm{Fe}^{3+}$ a Fe ${ }^{2+}$. $\mathrm{O} \mathrm{Fe}^{2+}$ produzido oxidou $\mathrm{O}_{2} \mathrm{a} \mathrm{O}_{2}{ }^{--}$, formando $\mathrm{H}_{2} \mathrm{O}_{2}$, a partir do qual foi gerado $\bullet \mathrm{OH}$ através da reação de Fenton. ${ }^{106,107}$

Quando este mesmo peptídeo e ferro foram incubados durante 30 min a $50{ }^{\circ} \mathrm{C}$ com carboximetilcelulose (CMC) a viscosidade da solução diminuiu praticamente pela metade, mas não foi detectada a formação de açúcares redutores. Quando papel de filtro foi utilizado como substrato, a diminuição do grau de polimerização foi pequena mesmo após 3 dias de incubação, porém, quando se utilizou fibra de algodão o poder redutor aumentou gradualmente ao longo do período de 5 dias de incubação. Após incubar fibra de algodão finamente moída e sem extrativos por 3 dias, os autores verificaram através de análises de FT-IR que algumas das ligações de hidrogênio entre os grupos - $\mathrm{OH}$ da celulose foram rompidas após tratamento com o peptídeo e ferro. Análises de raio-X evidenciaram que a cristalinidade do algodão reduziu 49,8\% e a microscopia eletrônica de varredura mostrou uma estrutura da celulose mais frouxa que no seu estado nativo, ${ }^{107}$ tornando-a mais susceptível à degradação, principalmente por via enzimática.

$\mathrm{O}$ mesmo peptídeo foi, também, incubado na presença de $\mathrm{Fe}^{3+}$ e lignina, e um ligeiro aumento na fração de baixa massa molar solúvel da lignina foi observado. Esse aumento foi proporcional à quantidade de peptídeo adicionada ao meio reacional. ${ }^{108}$ Os autores verificaram por espectrofotometria que a absorbância em 210 e 280 $\mathrm{nm}$ dos produtos solúveis aumentou, assim como ocorre nos ensaios com MnP e LiP. ${ }^{108} \mathrm{O}$ envolvimento de radicais hidroxila foi sugerido desde que a adição de sequestradores dos mesmos ao meio reacional promoveu uma diminuição da fração de baixa massa molar de lignina solúvel. ${ }^{108}$

Em um outro trabalho do mesmo grupo, frações $<5 \mathrm{kDa}$ foram isoladas de 57 fungos pertencentes a 34 espécies de fungos de decomposição branca, branda e parda, após extração com tampão acetato das culturas extracelulares obtidas em meio com material lignocelulósico. ${ }^{110}$ Todas as frações reagiram com o ácido tiobarbitúrico (TBA) proporcionando aumento de absorbância a $532 \mathrm{~nm}$, resultado que foi interpretado como um indicativo da produção de radicais hidroxila por peptídeos presentes nestas frações $<5 \mathrm{kDa}$. Esta observação levou os autores a sugerirem que a produção destes peptídeos de baixa massa 
molar capazes de catalisar reações que resultem na formação de $\bullet \mathrm{OH}$ é universal em fungos celulolíticos, ${ }^{110}$ embora nenhum ensaio tenha sido realizado para mostrar que os compostos presentes nas frações $<$ $5 \mathrm{kDa}$ que reagiram com TBA eram peptídeos. É importante ressaltar que o método TBA não é específico para a detecção da produção de radicais hidroxila, uma vez que diversos fatores podem afetar a intensidade da absorbância a $532 \mathrm{~nm}$.

Recentemente, este mesmo grupo isolou um peptídeo de baixa massa molar (600 Da) contendo os aminoácidos Glu, Gly e Val de culturas extracelulares de $P$. chrysosporium. ${ }^{37}$ Similarmente aos peptídeos previamente detectados pelo grupo, ${ }^{106-110}$ o peptídeo de $P$. chrysosporium foi capaz de quelar $\mathrm{Fe}^{3+}$ e reduzí-lo a $\mathrm{Fe}^{2+}$, porém se diferenciou pela elevada termoestabilidade, atividade em $\mathrm{pH}$ levemente alcalino, pelo fato de não reagir com TBA e ser capaz de oxidar vários compostos fenólicos modelo de lignina, como 2,6-dimetoxifenol, ácido 2,2'-azino-bis(3-etilbenzotiazolino-6-sulfônico) (ABTS) e siringaldazina, na ausência de $\mathrm{Mn}^{2+} \mathrm{e}_{2} \mathrm{O}_{2} \cdot{ }^{37} \mathrm{Um}$ metabólito de baixa massa molar com capacidade de oxidar compostos modelos de lignina na ausência de peróxido de hidrogênio foi, também, isolado por Machuca, Aoyama e Duran de culturas extracelulares do ascomiceto Thermoascus aurantiacus. ${ }^{111}$

Recentemente Arantes isolou das frações $<5 \mathrm{kDa}$ de fungos de decomposição branca e parda peptídeos de baixa massa molar com atividade redutora de $\mathrm{Fe}^{3+}$, entretanto, estes peptídeos não foram os principais compostos de baixa massa molar responsáveis pela atividade redutora detectada nos caldos de cultivo. ${ }^{64}$

\section{Compostos aromáticos quelantes e redutores de $\mathrm{Fe}^{3+}$}

A produção de compostos quelantes de ferro por fungos degradadores de madeira foi primeiramente demonstrada por Fekete, Chandhoke e Jellison. ${ }^{112}$ Em seguida, através de vários trabalhos o grupo de Goodell e Jellison determinou, a partir de compostos isolados de culturas extracelulares de G. trabeum, que estes quelantes são de baixa massa molar ${ }^{12,28,113-115}$ e que são principalmente compostos aromáticos como os derivados de ácido hidroxi-fenilacético, de ácido hidroxi-benzóico e de hidroxi-benzeno. ${ }^{12}$

Goodell et al., utilizando uma fração de baixa massa molar (< $1 \mathrm{kDa}$ ) contendo uma mistura destes compostos aromáticos obtidos de G. trabeum, mostraram que esta fração foi capaz de reduzir $\mathrm{Fe}^{3+}$ a $\mathrm{Fe}^{2+}$ e promover maior formação de radicais hidroxila (atividade pró-oxidante) entre ferro e peróxido de hidrogênio. ${ }^{12}$ Com base neste resultado e outros resultados prévios do grupo, os autores postularam a hipótese de que estes compostos aromáticos de baixa massa molar com capacidade de quelar e reduzir íons $\mathrm{Fe}^{3+}$ poderiam estar envolvidos em um sistema oxidativo não enzimático durante a degradação da madeira por fungos de decomposição parda, atuando através da mediação da reação de Fenton, para a geração de radicais hidroxila. $^{12}$

Resumidamente, a hipótese proposta pelo grupo de Goodell sugere que a hifa do fungo de decomposição parda crescendo no lúmen secreta ácido oxálico, quelantes aromáticos com atividade redutora de $\mathrm{Fe}^{3+}$ e peróxido de hidrogênio. Estes reagentes, então, difundem para a parede celular da madeira. $\mathrm{O}$ oxalato abaixa o $\mathrm{pH}$ $(\sim 2,5)$ do ambiente de degradação, criando um gradiente de $\mathrm{pH}$ através da parede celular da madeira. $\mathrm{O}$ oxalato quela o ferro ligado à celulose para formar complexos $\mathrm{Fe}$-oxalato solúveis, que difundem na parede celular (no sentido lúmen-lamela média) para uma região de $\mathrm{pH}$ mais elevado ( $\mathrm{pH} 4-4,5$ ). Nesta região, o ferro é sequestrado destes complexos pelos quelantes aromáticos e reduzido a $\mathrm{Fe}^{2+}$. $\mathrm{O}$ $\mathrm{Fe}^{2+}$ recém-gerado reage com peróxido de hidrogênio (reação de Fenton) para produzir radicais hidroxilas. Estes radicais produzidos a certa distância da hifa fúngica (protegendo o fungo contra o ataque oxidativo) são capazes de reagir tanto com a lignina quanto com os polissacarídeos presentes na parede celular da madeira. ${ }^{12}$

Recentemente Arantes et al. mostraram evidências experimentais que corroboram a teoria proposta pelo grupo de Goodell ao demonstrarem que ácido oxálico em elevadas concentrações é capaz de remover íons férricos presentes na madeira, e que complexos Feoxalato podem se difundir pela madeira, criando um gradiente de $\mathrm{pH}$. Além disso, ao se difundirem, os íons férricos estariam sendo transportados para uma região de $\mathrm{pH}$ menos ácido (resultado do gradiente de $\mathrm{pH}$ ) podendo, então, reagir com os compostos aromáticos redutores de ferro e promover a geração de radicais hidroxilas, via reação de Fenton. ${ }^{81}$

Através de vários trabalhos, o grupo de Hammel tem, também, apresentado evidências de que o fungo de decomposição parda $G$. trabeum possui um sistema oxidativo extracelular não enzimático, composto pela reação de Fenton mediada por compostos quelantes aromáticos com atividade redutora de $\mathrm{Fe}^{3+}$, para iniciar a biodegradação da madeira..$^{90,116-121}$ Dois compostos de baixa massa molar do tipo quinona foram isolados do cultivo de G. trabeum, 2,5-dimetoxi-1,4benzoquinona e 4,5-dimetoxi-1,2-benzoquinona e suas respectivas formas reduzidas, 2,5-dimetoxi-1,4-hidroquinona e 4,5-dimetoxi-1,2catecol. As formas reduzidas foram capazes de reduzir $\mathrm{Fe}^{3+} \cdot{ }^{118-120}$ Estas reações de óxido-redução envolvendo um elétron geraram radicais semiquinonas que foram posteriormente oxidados por outro íon $\mathrm{Fe}^{3+}$, formando as benzoquinonas e $\mathrm{Fe}^{2+}$. Nesta segunda etapa, $\mathrm{O}_{2}$ também pode atuar como um aceptor de elétrons, sendo reduzido pelo radical semiquinona a $\mathrm{HO}_{2}{ }^{\circ} / \mathrm{O}_{2}^{-}$, os quais podem ser convertidos a $\mathrm{H}_{2} \mathrm{O}_{2}$. Por fim, uma enzima presente no micélio reduziu estas quinonas para regenerar as hidroquinonas, que são necessárias para iniciar o ciclo de geração do reagente de Fenton. ${ }^{18,120}$

Uma quinona redutase dependente de NADH isolada do micélio de G. trabeum foi identificada como responsável por reduzir quinona a hidroquinona e usa 2,5-dimetoxi-1,4-benzoquinona e 4,5-dimetoxi1,2-benzoquinona como aceptores de elétrons. ${ }^{116,119,122}$ Considerando que o fungo utiliza esta enzima de membrana para regenerar hidroquinona e, consequentemente, produzir $\mathrm{Fe}^{2+} \mathrm{e}_{2} \mathrm{O}_{2}$, os radicais hidroxila estariam sendo formados muito próximo da hifa fúngica, os quais poderiam causar danos ao próprio fungo. Dessa forma, a menos que o fungo disponha de um sistema de difusão da hidroquinona para participar de reações que gerem $\mathrm{Fe}^{2+} \mathrm{e}_{2} \mathrm{O}_{2}$ distante do fungo e, consequentemente, um sistema de retorno da quinona para próximo da hifa, para que seja, então, reduzida regenerando a hidroquinona, é improvável que este sistema seja utilizado durante a biodegradação da madeira por fungos de decomposição parda.

Com exceção do fungo de decomposição parda Serpula lacrymans $^{123}$ e algumas espécies de Gloeophyllum, ${ }^{92}$ a teoria de que fungos de decomposição parda utilizam agentes quelantes aromáticos com atividade redutora de $\mathrm{Fe}^{3+}$ para mediar a reação de Fenton e gerar radicais hidroxila estava baseada principalmente nos compostos isolados e caracterizados de culturas extracelulares de um único fungo de composição parda, G. trabeum. ${ }^{12,28,90,113-121}$

Recentemente vários compostos fenólicos de baixa massa molar com atividade redutora de ferro foram purificados e identificados do cultivo do fungo de decomposição parda Wolfiporia cocos e branca seletivo $P$. medulla-panis, ${ }^{64,124-127}$ indicando que a produção de compostos aromáticos redutores de ferro não é característica somente de G. trabeum mas também de outros fungos degradadores de madeira, inclusive os de decomposição branca. Estes compostos foram utilizados na mediação da reação de Fenton para degradar polissacarídeos e lignina em sistemas similares às condições fisiológicas de fungos degradadores de madeira, nos quais íons férricos foram reduzidos in situ e o pH estava entre 4,0-5,0. ${ }^{64}$ A degradação da celulose foi caracterizada por uma rápida e extensiva despolimerização, seguida de significativa oxidação, e análises dos monômeros de lignina libe- 
rados de conífera tratada e não tratada após ${ }^{13} \mathrm{C}$-TMAH (hidróxido de tetra-metil-amônio) termoquimólise indicaram significativa oxidação da lignina, principalmente por desmetoxilação. ${ }^{64}$

Embora alguns estudos com $C$. subvermispora sugiram que a reação de Fenton mediada não esteja envolvida na biodegradação da madeira por fungos de decomposição branca, ${ }^{128}$ estudos mais recentes com diferentes fungos de decomposição branca indicam uma intensa ação sinérgica entre compostos de baixa massa molar com atividade redutora de $\mathrm{Fe}^{3+} \mathrm{e}$ as enzimas ligninolíticas lacase e manganês-peroxidase. ${ }^{127}$

Arantes e Milagres mostraram que quando Azure B (um composto recalcitrante, amplamente utilizado para detecção seletiva da atividade de lignina-peroxidase) é inicialmente tratado com compostos de baixa massa molar redutores de $\mathrm{Fe}^{3+}$ (parcialmente purificados de culturas de diferentes fungos de decomposição branca seletivos e simultâneos) juntamente com ferro e peróxido de hidrogênio, este sistema oxidativo (reação de Fenton mediada) proporciona alterações na estrutura do Azure B, resultando na formação de intermediário(s) que é(são) substrato(s) de lacase ou manganês-peroxidase, proporcionando assim, uma extensiva degradação deste composto altamente recalcitrante. ${ }^{127}$ Vale ressaltar que Azure B não é diretamente oxidado por lacase e nem por manganês-peroxidase. Este sinergismo evidenciado entre a reação de Fenton mediada com lacase/manganês peroxidase, apresenta-se como uma rota plausível para a completa degradação da lignina por fungos de decomposição branca deficiente em ligninaperoxidase, enzima esta com elevado potencial oxidativo e única entre as ligninases capazes de oxidar lignina não fenólica, que constitui entre $80-90 \%$ da estrutura da lignina em madeira.

Esse conjunto de trabalhos apresentados aqui aponta para uma participação expressiva da reação de Fenton mediada por compostos de baixa massa molar redutores de $\mathrm{Fe}^{3+}$ na biodegradação de polissacarídeos e lignina, tanto em fungos de decomposição parda quanto branca.

É possível que fragmentos de lignina produzidos durante a biodegradação parda de madeira possam também funcionar como fonte de elétrons para redução de $\mathrm{Fe}^{3+}$ a $\mathrm{Fe}^{2+} .{ }^{129}$ Sendo assim, a biodegradação parda poderia ser iniciada pela reação de Fenton mediada por compostos aromáticos fúngicos com atividade redutora de $\mathrm{Fe}^{3+} \mathrm{e}$, à medida que a degradação parda avança, os próprios fragmentos da lignina poderiam mediar futuras reações de Fenton. ${ }^{130}$

\section{Celobiose-desidrogenase ( $\mathrm{CDH})$}

$\mathrm{CDH}$, uma enzima pertencente ao complexo celulolítico, produzida principalmente por fungos de decomposição branca, oxida vários açúcares e reduz quinonas, $\mathrm{O}_{2}, \mathrm{Fe}^{3+} \mathrm{e} \mathrm{Cu}^{2+}$. Ao reduzir $\mathrm{Fe}^{3+}$ a $\mathrm{Fe}^{2+}$, o $\mathrm{Fe}^{2+}$ pode reagir com $\mathrm{H}_{2} \mathrm{O}_{2}$ (proveniente da redução de $\mathrm{O}_{2}$ pela própria $\mathrm{CDH}$ ou por outras enzimas produtoras de peróxido) gerando radicais hidroxilas via reação de Fenton, que podem atuar na despolimerização de polissacarídeos e na modificação estrutural da lignina. ${ }^{32,34}$

Hyde e Wood apresentaram um mecanismo envolvendo $\mathrm{CDH}$ no sistema Fenton para o fungo de decomposição parda Coniophora putanea. ${ }^{131} \mathrm{Na}$ proposta apresentada, a secreção de $\mathrm{CDH}$ por $C$. puteana fornece um mecanismo para a geração de $\mathrm{Fe}^{2+}$ na presença de oxalato. A reação requer um $\mathrm{pH}$ mais ácido $(\mathrm{pH}$ ao redor de 2,0$)$ do que o da própria madeira. $\mathrm{Em} \mathrm{pH}$ ácido, o $\mathrm{Fe}^{2+}$ recém-gerado a partir da redução de $\mathrm{Fe}^{3+}$ pela $\mathrm{CDH}$ é resistente à auto-oxidação e pode ter meia vida de $1 \mathrm{~h}$ ou mais. Durante este período, os autores postularam que ocorreria a difusão de $\mathrm{Fe}^{2+}$ a certa distância da hifa fúngica no sentido lúmen-lamela média, para uma região de $\mathrm{pH}$ menos ácido. Nesta região, o $\mathrm{Fe}^{2+}$ seria, então, auto-oxidado, através da transferência de um elétron do oxigênio molecular $\left(\mathrm{Fe}^{2+}+\mathrm{O}_{2} \rightarrow \mathrm{Fe}^{3+}\right.$ $\left.+\mathrm{O}_{2}^{\circ}\right)$ e o superoxiânion $\left(\mathrm{O}_{2}^{*}\right)$ formado seria rapidamente removido pela reação com $\mathrm{Fe}^{2+}$, resultando na formação de $\mathrm{H}_{2} \mathrm{O}_{2}\left(\mathrm{Fe}^{2+}+\mathrm{O}_{2}{ }^{\cdot-}+\right.$ $\left.2 \mathrm{H}^{+} \rightarrow \mathrm{Fe}^{3+}+\mathrm{H}_{2} \mathrm{O}_{2}\right)$. Assim, a parcial auto-oxidação criaria a combinação $\mathrm{Fe}^{2+} / \mathrm{H}_{2} \mathrm{O}_{2}$ permitindo que radicais hidroxila sejam gerados a certa distância da hifa. ${ }^{131}$

\section{APLICAÇÕES DOS SISTEMAS OXIDATIVOS DE BAIXA MASSA MOLAR}

Ao contrário das enzimas lignocelulolíticas produzidas por fungos degradadores de madeira que já encontram algumas aplicações consolidadas, possíveis aplicações dos sistemas degradativos não enzimáticos de baixa massa molar ainda estão em fase de estudo, mas resultados promissores já têm sido obtidos com a reação de Fenton mediada com compostos redutores de ferro e com o sistema lacase-mediador.

A característica principal da reação de Fenton mediada por um agente redutor de ferro é sua atividade pró-oxidante, proveniente da ação do agente redutor, que atua reduzindo $\mathrm{Fe}^{3+}$ a $\mathrm{Fe}^{2+}$, fazendo com que mais $\mathrm{Fe}^{2+}$ esteja prontamente disponível para reagir com peróxido de hidrogênio, ${ }^{12,132}$ assim, prolongando a primeira fase da reação de Fenton $\left(\mathrm{Fe}^{2+}+\mathrm{H}_{2} \mathrm{O}_{2} \mathrm{Fe}^{3+}+\mathrm{OH}+\cdot \mathrm{OH}, k=63 \mathrm{M}^{-1} \mathrm{~s}^{-1}\right)$, que é muitas vezes mais rápida que a segunda fase (reações envolvendo $\mathrm{Fe}^{3+}$ ), consequentemente resultando na maior formação de ROS e maior oxidação do composto alvo. ${ }^{132}$

Pracht et al. investigaram a relação entre a estrutura e a reatividade de vários compostos aromáticos, como catecol, guaiacol, hidroquinona e resorcinol, com $\mathrm{Fe}^{3+}$. Os autores mostraram que substratos fenólicos com dois grupos hidroxilas na posição orto ou pelo menos um grupo hidroxila e/ou um grupo metoxila podem ser oxidados a $\mathrm{CO}_{2}$ enquanto $\mathrm{Fe}^{3+}$ é reduzido e, ainda, concluíram que a mineralização do composto aromático a partir de múltiplas reduções de $\mathrm{Fe}^{3+}$ depende da posição dos grupos hidroxila. ${ }^{133}$

$\mathrm{O}$ primeiro relato mostrando a oxidação de xenobióticos pela reação de Fenton catalisada por agentes redutores de ferro foi apresentado há pouco mais de 50 anos por Hamilton et al. ${ }^{134}$ Porém, somente após a descoberta de que este sistema oxidativo poderia estar envolvido na biodegradação da madeira causada por fungos de decomposição branca e parda, há pouco mais de uma década, é que alguns pesquisadores começaram a estudar o potencial da reação de Fenton mediada. Nestes estudos foram utilizados principalmente derivados de fenois e 1,2-benzenodiol (catecol), como um possível processo oxidativo avançado (POA).

Uma fração de baixa massa molar $(<1 \mathrm{kDa})$ obtida da cultura de G. trabeum, contendo compostos do tipo catecol e com capacidade de quelar e reduzir $\mathrm{Fe}^{3+}$, foi utilizada na presença de $\mathrm{H}_{2} \mathrm{O}_{2} \mathrm{e} \mathrm{Fe}^{3+}$ (ou $\mathrm{Fe}^{2+}$ ) para degradar pentaclorofenol (PCP) em pH 4,0, e mostrou-se mais eficiente na degradação de PCP do que a reação de Fenton convencional $\left(\mathrm{Fe}^{2+}\right.$ e $\left.\mathrm{H}_{2} \mathrm{O}_{2}\right) \cdot{ }^{12}$ Vários outros trabalhos recentes têm demonstrando a eficiência da reação de Fenton mediada em comparação com a reação de Fenton convencional na degradação de efluentes industriais, ${ }^{135,136}$ corantes sintéticos ${ }^{132,135,137}$ polissacarídeos $^{138}$ e compostos modelo de lignina. ${ }^{135}$ Estes trabalhos demonstram que a reação de Fenton na presença de uma determinada quantidade de agente redutor, além de ser mais eficiente do que a reação de Fenton, amplia a faixa de $\mathrm{pH}$ em que a reação é eficiente (de $\mathrm{pH}$ 2-3 para $\mathrm{pH} 3-9) .{ }^{132}$

O sistema lacase-mediador tem sido utilizado na deslignificação de polpas, ${ }^{139-143}$ na degradação de corantes têxteis, ${ }^{144,145}$ de hidrocarbonetos aromáticos, ${ }^{146}$ de pesticidas e inseticidas,,${ }^{147,148} \mathrm{e} \mathrm{em}$ síntese orgânica. ${ }^{149,150} \mathrm{Na}$ indústria de polpa e papel, as tecnológicas de branqueamento enzimático apresentam grandes vantagens pela substituição das etapas de branqueamento com cloro. 


\section{CONCLUSÕES}

As modificações físicas, químicas e morfológicas observadas na madeira biodegradada por fungos de decomposição branca e parda não podem ser explicadas unicamente por ação enzimática. Neste sentido, este revisão agrupou as mais recentes teorias envolvendo compostos de baixa massa molar que buscam elucidar o completo sistema oxidativo empregado por fungos durante a biodegradação da madeira. Embora a função exata de cada um desses compostos ainda não seja conhecida, pode-se concluir que estes fungos dispõem de vários sistemas oxidativos não enzimáticos de baixa massa molar que são fundamentais para o processo global da biodegradação da madeira, contribuindo através de ação direta ou sinérgica com as enzimas lignocelulolíticas.

Devido à grande aplicabilidade destes sistemas degradativos envolvendo estes compostos de baixa massa molar, mais pesquisas são necessárias no intuito de elucidar os mecanismos químicos e bioquímicos envolvidos no processo de biodegradação com especial atenção aos compostos de baixa massa molar, buscando, dessa forma, a introdução de novas aplicações assim como a melhora das já existentes.

\section{AGRADECIMENTOS}

À Fundação de Amparo à Pesquisa do Estado de São Paulo (FAPESP) e à Coordenação de aperfeiçoamento de pessoal de nível superior do Ministério da Educação (CAPES). V. Arantes agradece especialmente à FAPESP, processo 04/12080-0.

\section{REFERÊNCIAS}

1. Pointing, S. B.; Appl. Microbiol. Biotechnol. 2001, 57, 20.

2. Archibald, F. S.; Paice, M. G.; Jurasek, L.; Enzyme Microb. Technol. 1990, $12,846$.

3. Duran, N.; Esposito, E.; Appl. Catal. B 2000, $28,83$.

4. Andersson, B. E.; Appl. Microbiol. Biotechnol. 1996, 46, 647.

5. Allard, A. -S.; Neilson, A. H.; Int. Biodeterior. Biodegrad. 1997, 39, 253.

6. Hatakka, A.; Maijala, P.; Mettälä, A.; Hakala, T.; Hauhio, L.; Ellmén, J.; Prog. Biotechnol. 2002, 21, 81.

7. Ferraz, A.; Guerra, A.; Mendonça, R.; Masarin, F.; Vicentim, M. P.; Aguiar, A.; Pavan, P. C.; Enzyme Microb. Technol. 2008, 43, 178.

8. Milagres, A. M. F.; Arantes, V.; Medeiros, C. L.; Machuca, A.; Enzyme Microb. Technol. 2002, 30, 562 .

9. Bajpai, P.; Crit. Rev. Biotechnol. 2004, 24, 1.

10. Moreira, M. T.; Feijoo, G.; Sierra-Alvarez, R.; Field, J. A.; Bioresour. Technol. 1999, 70, 255.

11. Blanchette, R. A.; Krueger, E. W.; Haight, J. E.; Akhtar, M.; Akin, D. E.; J. Biotechnol. 1997, 53, 203.

12. Goodell, B.; Jellison, J.; Liu, J.; Daniel, G.; Paszczynski, A.; Fekete, F.; Krishnamurthy, S.; Jun, L.; Xu, G.; J. Biotechnol. 1997, 53, 133.

13. Fengel, D.; Wegener, G.; Wood: Chemsitry, ultrastructure, reactions, Walter de Gruyter: Berlin, 1989.

14. Blanchette, R. A. Em The structural conservation of panel paintings: proceedings of a symposium at the J. Paul Getty Museum; Dardes, K.; Rothe, A., eds.; Getty Conservation Institute: Los Angeles, 1998.

15. Blanchette, R. A.; Int. Biodeterior. Biodegrad. 2000, 46, 189.

16. Schwarze, F. W. M. R.; Fungal Biology Rev. 2007, 21, 133.

17. Gilbertson, R. L.; Mycologia 1980, 72, 1.

18. Worrall, J. J.; Anagnost, S. E.; Zabel, R. A.; Mycologia 1997, 89, 199.

19. Daniel, G. Em Wood Deterioration and Preservation - Advances in our Changing World; Goodell, B.; Nicholas, D. D.; Schultz, T. P., eds.; ACS Symp. Ser 845, American Chemical Society: Washington, 2003.

20. Blanchette, R. A.; Ann. Rev. Phytopathol. 1991, 29, 381.

21. Eriksson, K. E. L.; Blanchette, R. A.; Ander, P.; Biodegradation of lignin. Microbial and enzymatic degradation of wood and wood components, Springer-Verlag: Berlin, 1990.
22. Rayner, A. D. M.; Boddy, L.; Fungal Decomposition of Wood: its Biology and Ecology, John Wiley: Chichester, 1988.

23. Ander, P.; Stoytschev, I.; Eriksson, K. E.; Cellul. Chem. Technol. 1988, $22,255$.

24. Enoki, A.; Tanaka, H.; Fuse, G.; Holzforchung 1988, 42, 85.

25. Blanchette, R. A.; Obst, J. R.; Timell, T. E.; Holzforschung 1994, 48, 34.

26. Machuca, M.; Ferraz, A.; Enzyme Microbial Technol. 2001, 29, 386

27. Highley, T. L.; Murmanis, L. L.; Palmer, J. G.; Holzforschung 1985, 39, 73.

28. Xu, G.; Goodell, B.; J. Biotechnol. 2001, 27, 43

29. Kirk, T. K.; Cullen, D.; Environmentally friendly technologies for the pulp and paper industry, New York, John Wiley and Sons: New York, 1998

30. Cullen, D.; Kersten, P. J.; The Mycota III Biochemistry and Molecular Biology, Springer-Verlag: Berlin, 2004.

31. Enoki, A.; Itajura, S.; Tanaka, H.; J. Biotechnol. 1997, 53, 265.

32. Henriksson, G.; Johansson, G.; Pettersson, G.; J. Biotechnol. 2000, 78, 93.

33. Vries, R. P.; Visser, J.; Microbiol. Mol. Biol. Rev. 2001, 65, 497.

34. Kuhad, R. C.; Singh, A. W.; Eriksson, K. E. L.; Advances in Biochemical Engineering/Biotechnology, Springer-Verlag Heidelberg: New York, vol. 57, 1997.

35. Martínez, A.; Enzyme Microb. Technol. 2002, 30, 425.

36. Kersten, P. J.; Kirk, T. K.; J. Bacteriol. 1987, 169, 2195.

37. Hu, G.; Zhang, W.; Lu, X.; Gao, P.; Sci. China: Ser. C Life Sci. 2006, 49,1 .

38. Srebotnik, E.; Boisson, J. -N.; Enzyme Microb. Technol. 2005, 36, 785.

39. Messner, K.; Srebotnik, E.; FEMS Microbiol. Rev. 1994, 13, 351.

40. Poulos, T. L.; Edwards, S. L.; Wariishi, H.; J. Biolog. Chem. 1993, 268, 4429 .

41. Harvey, P. J.; Schoemaker, H. E.; Palmer, J. M.; FEBS Lett. 1986, 195, 242.

42. ten Have, R.; Teunissen, P. J. M.; Chem. Rev. 2001, 101, 3397.

43. Bourbonnais, R.; Paice, M. G.; Appl. Microbiol. Biotechnol. 1992, 36, 823.

44. Potthast, A.; Rosenau, T.; Chen, C. L.; Gratzl, J. S. J.; Org. Chem. 1995 , $60,4320$.

45. Banci, L.; Ciofi-baffoni, S.; Tien, M.; Biochem. 1999, 38, 3205.

46. Cantarella, G.; Galli, G.; Gentili, C.; J. Mol. Catal. B 2003, 22, 135.

47. Eggert, C.; Temp, U.; Dean, J. F.; Eriksson, K. -E. L.; FEBS Lett. 1996 , $391,144$.

48. Li, K.; Horanyi, P.; Collins, R.; Phillips, R. S.; Eriksson, K. -E. L.; Enzyme Microb. Technol. 2001, 28, 301.

49. Camarero, S.; Ibarra, D.; Martínez, A. T.; Romero, J.; Gutíerrez, A.; Del Río, J. C.; Enzyme Microb. Technol. 2007, 40, 1264.

50. Shimada, M.; Fumiakin, M.; Kirk, T. K.; Higuchi, T.; Arch. Microbiol. 1981, 129, 321

51. Zapanta, L. S.; Tien, M.; J. Biotechnol. 1997, 53, 93.

52. Jong, E.; Field, J. A.; Bont, J. A. M.; FEMS Microbiol. Rev. 1994, 13, 153.

53. Gilardi, G.; Harvey, P. J.; Cass, A. E. G.; Palmer, J. M.; Biochim. Biophys. Acta 1990, 1041, 129.

54. Khindaria, A.; Grover, T. A.; Aust, S. D.; Biochem. 1995, 34, 6020.

55. Baciocchi, E.; Bietti, M.; Steenken, S.; J. Phys. Chem. A. 1998, 102, 7337.

56. Baciocchi, E.; Bietti, M.; Gerini, M. F.; Lanzalunga, O.; Biochem. Biophys. Res. Commun. 2002, 293, 832.

57. Candeias, L. P.; Harvey, P. J.; J. Biol. Chem. 1995, $270,16745$.

58. Khindaria, A.; Yamazaki, I.; Aust, S. D.; Biochem. 1996, 35, 6418.

59. Khindaria, A.; Yamazaki, I.; Aust, S. D.; Biochem. 1995, 34, 16860.

60. Popp, J. L.; Kalyanaraman, B.; Kirk, T. K.; Biochem. 1990, 29, 10475.

61. de Jong, E.; Field, J.; Annu. Rev. Microbiol. 1997, 51, 375.

62. Teunissen, P. J. M.; Field, J. A.; Appl. Env. Microbiol. 1998, 64, 830.

63. Teunissen, P. J.; Sheng, D.; Reddy, G. V.; Moenne-Loccoz, P.; Field, J. A.; Gold, M. H.; Arch. Biochem. Biophys. 1998, 360, 233.

64. Arantes, V.; Tese de Doutorado, Universidade de São Paulo, Brasil, 2008

65. Hammel, K. E.; Kapich, A. N.; Jensen Jr., K. A.; Ryan, Z. C.; Enzyme Microb. Technol. 2002, 30, 445.

66. Hofrichter, M.; Enzyme Microb. Technol. 2002, 30, 454. 
67. Jensen Jr. K. A.; Bao, W.; Kawai, S.; Srebotnik, E.; Hammel, K. E.; Appl. Environ. Microbiol. 1996, 62, 3679.

68. Kapich, A. N.; Jensen, K. A.; Hammel, K. E.; FEBS Lett. 1999, 461, 115.

69. Srebotniki, E.; Jensen Jr., K. E.; Kawai, S.; Hammel, K. E.; Appl. Environ. Microbiol. 1997, 63, 4435.

70. Watanabe, T.; Katayama, S.; Enoki, M.; Honda, Y. H.; Kuwahara, M.; Eur. J. Biochem. 2000, 267, 4222.

71. Lima, E. S.; Abdalla, D. S. P.; Rev. Bras. Cien. Farm. 2001, 37, 293.

72. Braughler, J. M.; Duncan, L. A.; Chase, R. L.; J. Biol. Chem. 1986, 261, 10282.

73. Kapich, A. N.; Galkin, S.; Hatakka, A.; Biocat. Biotransform. 2007, 25, 350 .

74. Hofrichter, M.; Vares, T.; Kalsi, M.; Galkin, S.; Scheibner, K.; Fritsche W.; Hatakka, A.; Appl. Environ. Microbiol. 1999, 65, 1864.

75. Urzúa, U.; Kersten, P. L.; Vicuna, R.; Appl. Environ. Microbiol. 1998, $64,68$.

76. Lequart, C.; Kurek, B.; Debeire, P.; Monties, B.; J. Agric. Food Chem. 1998, 46, 3868.

77. Meyer-Pinson, V.; Ruel, K.; Gaudard, F.; Valtat, G.; Petit-Conil, M.; Kurek, B.; C. R. Biol. 2004, 327, 917.

78. Jellison, J.; Connolly, J.; Goodell, B.; Doyle, B.; Illman, B.; Fekete, F.; Ostrofsky, A.; Inter. Biodeter. Biodegr. 1997, 39, 165.

79. Messner, K.; Fackler, K.; Lamaipis, P.; Gindl, W.; Srebotnik, E.; Watanable, T.; Proceedings do $7^{\text {th }}$ Brazilian symposium on the chemistry of lignins and other wood components, Belo Horizonte, Brasil, 2001.

80. Schmidt, C. J.; Whitten, B. K.; Nicholas, D. D.; Am. Wood Preserv. Assoc. 1981, 77, 157.

81. Arantes, V.; Qian, Y.; Milagres, A. M. F.; Jellison, J.; Goodell, B.; Inter Biodeter. Biodegr. 2009, no prelo.

82. Halliwell, G.; Biochem. J. 1965, 95, 35.

83. Koenigs, J. W.; Wood Fibre 1974, 6, 66.

84. Koenigs, J. W.; Biotechnol. Bioeng. Symp. 1975, 5, 151.

85. Koenigs, J. W.; Mater. Org. 1972, 7, 133.

86. Koenigs, J. W.; Phytopathology 1972, 62, 100.

87. Koenigs, J. W.; Arch. Microbiol. 1974, 99, 129.

88. Highley, T. L.; Mater. Org. 1977, 12, 25.

89. Kirk, T. K.; Ibach, M. D.; Mozuch, A. H. C.; Highley, T. L.; Holzforschung 1991, 45, 239.

90. Cohen, R.; Jensen, K. A.; Houtman, C. J.; Hammel, K. E.; FEBS Lett 2002, 531, 483 .

91. Kramer, C.; Kreisel, G.; Fahr, K.; Kassbohrer, J.; Schlosser, D.; Appl. Microbiol. Biotechnol. 2004, 64, 387.

92. Newcombe, D.; Paszczynski, A.; Gajewska, W.; Kroger, M.; Feis, G.; Crawford, R.; Enzyme Microb. Technol. 2002, 30, 506.

93. Schlosser, D.; Fahr, K.; Karl, W.; Wetzstein, H.; Appl. Environ. Microbiol. 2000, 66, 2479 .

94. Wetzstein, H. -G.; Schmeer, N.; Karl, W.; Appl. Environ. Microbiol. $\mathbf{1 9 9 7 , 6 3 , 4 2 7 2 . ~}$

95. Ek, M.; Gierer, J.; Jansbo. K.; Holzforschung 1989, 43, 391.

96. Gierer J.; Holzforschung 1990, 44, 387.

97. Tatsumi, K.; Terashima, N.; Mokuzai Gakkaishi 1985, 31, 316.

98. Filley, T. R.; Hatcher, P. G.; Shortle, W. C.; Praseuth, R. T.; Org. Geochem. 2000, 31, 181.

99. Enoki, A.; Tanaka, H.; Fuse, G.; Wood Sci. Technol. 1989, 23, 1.

100. Enoki, A.; Hirano, T.; Tanaka, H.; Mater. Org. 1992, 27, 247.

101. Hirano, T.; Enoki, A.; Tanaka, H.; J. Wood Sci. 2000, 46, 45.

102. Hirano, T.; Tanaka, H.; Enoki, A.; Mokuzai Gakkaishi 1995, 41, 334

103. Tanaka, H.; Fuse, G.; Enoki, A.; Mokuzai Gakkaishi 1991, 37, 986.

104. Tanaka, H.; Itakura, S.; Hirano, T.; Enoki, A.; Holzforschung 1996, 50, 541.

105. Tanaka, H.; Itakura, S.; Enoki, A.; J. Biotechnol. 1999, 75, 57.

106. Wang, W.; Gao, P.; Biodegrad 2002, 13, 383.

107. Wang, W.; Gao, P. J.; J. Biotechnol. 2003, 101, 119.

108. Wang, W.; Huagn, F.; Lu, X. M.; Gao, P. J.; Biotechnol. J. 2006, 1, 447

109. Wang, W.; Liu, J. C.; Gao, P. J.; Chin. Chem. Lett. 2002, 13, 773.

110. Yang, W.; Liu, J.; Wang, W.; Zhang, Y.; Gao, P.; Biotechnol. Lett. 2004, 26, 1799.
111. Machuca, A.; Aoyama, H.; Durán, N.; Biochem. Biophys. Res. Commun. 1999, 256, 20

112. Fekete, F. A.; Chandhoke, V.; Jellison, J.; Appl. Environ. Microbiol. 1989, 55, 2720 .

113. Chandhoke, V.; Goodell, B.; Jellison, J.; Fekete, F. A.; FEMS Microbiol. Lett. 1992, 90, 263

114. Jellison, J.; Chandhoke, V.; Goodell, B.; Fekete, F. A.; Appl. Microbiol. Biotechnol. 1991, 35, 805.

115. Paszczynski, A.; Crawford, R.; Funk, D.; Goodell, B.; Appl. Environ. Microbiol. 1999, 65, 674.

116. Cohen, R.; Suzuki, M. R.; Hammel, K. E.; Appl. Environ. Microbiol. 2004, 70, 324

117. Kerem, Z.; Bao, W.; Hammel, K. E.; Proc. Nat. Acad. Sci. U.S.A. 1998, 95,10373

118. Kerem, Z.; Jensen, K. A.; Hammel, K. E.; FEBS Lett. 1999, 446, 49

119. Jensen Jr., K. A.; Ryan, Z. C.; Wymelenberg, A. V.; Cullen, D.; Hammel, K. E.; Appl. Environ. Microbiol. 2002, 68, 2699.

120. Jensen, K. A.; Houtman, C. J.; Ryan, Z. C.; Hammel, K. E.; Appl. Microbiol. Biotechnol. 2001, 67, 2705.

121. Suzuki, M. R.; Hunt, C. G.; Houtman, C. J.; Dalebroux, Z. D.; Hammel, K. E.; Environ. Microbiol. 2006, 8, 2214

122. Qi, W.; Jellison, J.; Inter. Biodeter. Biodegrad. 2004, 54, 53.

123. Shimokawa, T.; Nakamura, M.; Hayashi, N.; Ishihara, M.; Holzforschung 2004, 58, 305.

124. Arantes, V.; Milagres, A. M. F.; Process Biochem. 2006, 41, 887.

125. Arantes, V.; Milagres, A. M. F.; Can. J. Microbiol. 2007, 53, 1323.

126 Arantes, V.; Milagres, A. M. F.; J. Appl. Microbiol. 2008, 104, 185.

127. Arantes, V.; Milagres, A. M. F.; Enzyme Microb. Technol. 2007, 42, 17.

128. Watanabe, T.; Teranishi, H.; Honda, Y.; Kuwahara, M.; Biochem. Biophys. Res. Commun. 2002, 297, 918.

129. Filley, T. R.; Cody, G. D.; Goodell, B.; Jellison, J.; Noser, C.; Ostrofsky, A.; Org. Geochem. 2002, 33, 111.

130. Goodell, B.; Daniel, G.; Jellison, J.; Qian, Y.; Holzforschung 2006, 60, 630

131. Hyde, S. M.; Wood, P. M.; Microbiology 1997, 143, 259.

132. Arantes, V.; Baldochi, C.; Milagres, A. M. F.; Chemosphere 2006, 63, 1764.

133. Pracht, J.; Boenigk, J.; Isenbeck-Schroter, M.; Keppler, F.; Scholer, H. F.; Chemosphere 2001, 44, 613.

134. Hamilton, G. A.; Hanafin, J. W.; Friedman, J.; J. Am. Chem. Soc. 1966, $88,5269$.

135. Arantes, V.; Milagres, A. M. F.; J. Hazard. Mater. 2007, 141, 273.

136. Arantes, V.; Milagres, A. M. F.; Water Sci. Technol. 2007, 55, 1.

137. Aguiar, A.; Ferraz, A.; Chemosphere 2007, 66, 947.

138. Arantes, V.; Milagres, A. M. F.; J. Chem. Technol. Biotechnol. 2006, 30, 562.

139. Bourbonnais, R.; Leech, D.; Paice, M. G.; Biochim. Biophys. Acta 1998, 1379,381

140. Call, H. P.; Mucke, I.; J. Biotechnol. 1997, 53, 163.

141. Crestini, C. L.; Argyropoulos, D. S.; Bioorg. Med. Chem. 1998, 6, 2161.

142. Sealey, J.; Ragauskas, A. J.; Enzyme Microb. Technol. 1998, 23, 422.

143. Li, K.; Xu, F.; Erikssen, K. E. L.; Appl. Environ. Microbiol. 1999, 65, 2654.

144. Wesenberg, D.; Kyriakides, I.; Agathos, S. N.; Biotechnol. Adv. 2003, 22,161 .

145. Camarero, S.; Ibarra, D.; Martinez, M. J.; Martinez, A. T.; Appl. Environ. Microbiol. 2005, 71, 1775.

146. Johannes, C.; Majcherczyk, A.; Hüttermann, A.; Appl. Microbiol. Biotechnol. 1996, 46, 313 .

147. Amitai, G.; Adani, R.; Sod-Moriah, G.; Rabinovitz, I.; Vincze, A.; Leader, H.; Chefetz, B.; Leibovitz-Persky, L.; Friesem, D.; Hadar, Y.; FEBS Lett. 1998, 438, 195

148. Kang, K. H.; Dec, J.; Park, H.; Bollag, J. M.; Water Res. 2002, 36, 4907.

149. Fritz-Langhals, E.; Kunath, B.; Tetrahedron Lett. 1998, 39, 5955.

150. Potthast, A.; Rosenau, T.; Chen, C. L.; Gratzl, J. S.; J. Mol. Catal. A 1996, 108,5 . 